\title{
Perioperative Beta-blocker and Statin use in Patients with Coronary Artery Disease Undergoing Orthotopic Liver Transplantation
}

\author{
Stephen J Bagley ${ }^{1}$, Meredith Grzybowski ${ }^{2}$, Andrew J Litwack ${ }^{3}$ and Scott M. Lilly ${ }^{4 *}$ \\ ${ }^{1}$ Department of Medicine, University of Pennsylvania, Philadelphia, PA 19104, USA \\ ${ }^{2}$ Penn Transplant Institute, University of Pennsylvania, Philadelphia, PA 19104, USA \\ ${ }^{3}$ Department of Medicine, Cardiovascular Division, University of Pennsylvania, Philadelphia, PA 19104, USA \\ ${ }^{4}$ Division of Cardiovascular Medicine, Heart and Vascular Center, Ohio State University, Columbus, OH 43210, USA
}

Received: October 25, 2013; Accepted: July 15, 2014, Published: August 01, 2014

*Corresponding author: Scott M. Lilly, Interventional Cardiology, Division of Cardiovascular Medicine, Heart and Vascular Center, 473 W. 12 th Avenue, Suite 200, OH 43210-1252,Columbus, USA, Tel: +614-293-4146; Fax: 614-292-1518; E-mail: scott.lilly@osumc.edu

\begin{abstract}
Background: In patients that undergo Orthotopic Liver Transplantation (OLT), the presence of Coronary Artery Disease (CAD) is associated with worse short- and long-term outcomes. With reported 3-year mortality rates up to $50 \%$, recent efforts have focused on ways to reduce perioperative cardiovascular risk in this population. While continuation of Beta-Blocker (BB) and statin therapy has been shown to benefit patients with known CAD undergoing intermediate or high-risk noncardiac surgery, it is unknown whether these therapies benefit patients with CAD undergoing OLT.

Methods: We retrospectively identified 45 patients that underwent OLT between 2002 and 2010 with known CAD. Records were reviewed and patterns of BB (uninterrupted therapy, interrupted therapy no therapy, at hospital discharge) and statin (preoperative, at hospital discharge) use were categorized as indicated. Chi-square, Fisher's exact test, and ANOVA were employed to compare patterns of use with Length of Stay (LOS), as well as the incidence of death, Myocardial Infarction (MI), and composite death and Myocardial Infarction (MI) at both 30 days and 12 months post-OLT.

Results: Thirty-three patients (73\%) were on a BB at admission, and of these 20 (61\%) had BB therapy withheld for > 48 hours. Twenty-seven $(60 \%)$ patients were discharged on a BB. Eight patients out of $45(18 \%)$ were on statin therapy chronically and had the drug continued till the time of OLT. Following transplantation, 1 patient (2\%) was discharged on a statin. Overall there were $5(11 \%)$ in-hospital MI in the cohort. Of these, none occurred in patients given continuous BB therapy, while 4 occurred in patients that had BB therapy withdrawn $(\mathrm{p}=0.118)$ and 1 in a patient never administered BB. On univariate analysis, mean LOS differed with respect to BB use and was longer in those that had interrupted ( $20.3 \pm 13.9$ days) compared with uninterrupted BB therapy $(11.5 \pm 7.1 ; \mathrm{p}=0.020)$. Composite 1-year mortality and MI was $22 \%$ and did not differ with regard to BB or statin prescription at the time of discharge.

Conclusions: In patients with CAD undergoing OLT there is a high rate of perioperative BB withdrawal. In addition, few patients are on statin therapy at the time of OLT, and most are not administered a statin postoperatively. BB withdrawal in this population was associated with a non-significant increase in 30-day MI and a significant increase in LOS. This observation, from the largest CAD-OLT cohort yet reported, calls for identifying reasons for BB withdrawal and provides support for increased vigilance with respect to BB provision in this population.
\end{abstract}

\section{Introduction}

Patients with End-Stage Liver Disease (ESLD) have a prevalence of Coronary Artery Disease (CAD) up to 27\% , exceeding that of the general population [1-4 ]. Moreover, patients with CAD undergoing Orthotopic Liver Transplantation (OLT) experience worse short and long-term outcomes compared to those without CAD [5-7]. While these prognostic implications may limit transplant eligibility, OLT is still frequently offered to patients with CAD [8].

There are few guidelines that address the perioperative management of cardiovascular risk in this specific population $[9,10]$. Established guidelines do exist for the perioperative management of patients with known CAD undergoing intermediate or high-risk noncardiac surgery. These include the continuation of $\mathrm{BB}$ and statin therapy throughout the perioperative period in an effort to reduce cardiovascular events [11]. However, the adherence and utility of this practice is unknown in the OLT population, as BB therapy may be initiated primarily due to concern for variceal bleeding and statin therapy may be withheld due to concern for hepatotoxicity.

The present study was undertaken to describe patterns of beta-blocker and statin use among patients with CAD undergoing OLT at a tertiary care hospital. In addition, we sought to evaluate 
the impact of perioperative $\mathrm{BB}$ and statin use on outcomes following OLT in this population.

\section{Methods}

After institutional review board approval and the granting of a waiver of informed consent, we searched the institutional transplant database for patients who underwent OLT at the Hospital of the University of Pennsylvania between 2002 and 2010. This search produced a list of 1,075 patients, which was then cross-referenced to a list of all inpatients and outpatients in the University of Pennsylvania Health System who were billed for an ICD-9 diagnostic code related to CAD between 1998 and 2010. These codes included: "acute myocardial infarction", "other acute and subacute forms of ischemic heart disease", "old myocardial infarction", "angina pectoris", "other forms of chronic ischemic heart disease", "aortocoronary bypass status", and "percutaneous transluminal coronary angioplasty status". This cross-reference yielded 251 patients who had undergone OLT between 2002 and 2010 and had been billed for a diagnosis or related diagnosis of CAD (either before or after OLT). Each of these 251 charts was then manually evaluated to corroborate the existence of known CAD, as defined in Table 1, at the time of the patient's OLT. A total of 47 patients met the criteria for analysis. Two of these patients were excluded because they underwent simultaneous liver and heart transplants, leaving 45 patients included in the study.

These 45 patients additionally had their medical records reviewed for the use of a beta blocker or statin 1) during the 30 days prior to hospitalization for OLT; 2 ) at the time of admission for OLT; 3) during hospitalization for OLT; 4) at discharge from OLT hospitalization; and 5) following discharge up to 30 days posttransplant. Ordinal variables were created for BB use, including "uninterrupted therapy", "interrupted therapy" (defined in Table 1), "no therapy", and " at hospital discharge", and for statin use, including "preoperative" and "at hospital discharge". Chisquare, Fisher's exact test, and analysis of variance (ANOVA) were employed to compare BB and statin use with the following outcomes: 1) myocardial infarction (MI, as defined in Table 1) at 30 days and 12 months post-OLT, 2) mortality at 30 days and 12 months, 3) composite death and myocardial infarction at 30 days and 12 months, and 4) length of hospital stay (LOS).

\section{Results}

Baseline characteristics are listed in Table 2. The cohort predominantly comprised of Caucasian males (91\%), with a mean age of 61 years. The most common etiologies for ESLD were viral hepatitis (33\%) and non alcoholic steatohepatitis (33\%). Thirtysix percent of the patients had a history of coronary artery bypass grafting (CABG), 33\% had a history of percutaneous coronary intervention (PCI), 24\% had been managed medically with an obstructive lesion, $\geq 50 \%$ on coronary angiography, and the remaining $7 \%$ had been managed medically with a documented history of myocardial infarction. No patients were allergic to beta-blockers. One patient had charted allergies to atorvastatin and rosuvastatin.

The rates of BB and statin use are listed in Table 3. Thirtythree patients in our cohort (73\%) were on a BB at admission,
Table 1: Definitions

\begin{tabular}{|c|c|}
\hline & Definitions \\
\hline $\begin{array}{c}\text { Coronary } \\
\text { artery } \\
\text { disease }\end{array}$ & $\begin{array}{l}\text { Any one or more of the following: } 1 \text { ) history of } \geq \\
1 \text { documented MI, 2) history of coronary artery } \\
\text { bypass grafting (CABG), 3) history of percutaneous } \\
\text { coronary intervention (coronary artery angioplasty } \\
\text { with or without stenting), } 4 \text { ) coronary angiography } \\
\text { demonstrating } \geq 1 \text { significant lesion causing } \geq 50 \% \\
\text { stenosis }\end{array}$ \\
\hline $\begin{array}{c}\text { Myocardial } \\
\text { infarction }\end{array}$ & $\begin{array}{l}\text { Detection of rise in serum cardiac biomarkers (troponin } \\
\text { T) with any of the following evidence of ischemia: 1) } \\
\text { chest pain, 2) ECG ST-T wave changes indicative of } \\
\text { ischemia, 3) development of pathologic Q waves on ECG, } \\
\text { 4) imaging evidence of new loss of viable myocardium or } \\
\text { new regional wall motion abnormality }{ }^{23}\end{array}$ \\
\hline
\end{tabular}

Table 2: Baseline Demographic and Clinical Features.

\begin{tabular}{|c|c|}
\hline Mean Age (yrs) & $61 \pm 5.9$ \\
\hline Men & $38(84 \%)$ \\
\hline Women & $7(16 \%)$ \\
\hline \multicolumn{2}{|l|}{ Race } \\
\hline White & $41(91 \%)$ \\
\hline Black & $3(7 \%)$ \\
\hline Hispanic & $0(0 \%)$ \\
\hline Other & $1(2 \%)$ \\
\hline \multicolumn{2}{|l|}{ Etiology of ESLD } \\
\hline Non alcoholic steatohepatitis & $15(33 \%)$ \\
\hline Viral hepatitis & $15(33 \%)$ \\
\hline Cryptogenic & $5(11 \%)$ \\
\hline Alcoholic & $5(11 \%)$ \\
\hline Other & $5(11 \%)$ \\
\hline \multicolumn{2}{|l|}{ Coronary risk factors } \\
\hline Hypertension & $27(60 \%)$ \\
\hline Diabetes Mellitus & $26(58 \%)$ \\
\hline Current or previous smoker & $34(76 \%)$ \\
\hline Hyperlipidemia & $12(27 \%)$ \\
\hline \multicolumn{2}{|l|}{ Evidence of CAD } \\
\hline CABG & $16(36 \%)$ \\
\hline PCI & $15(33 \%)$ \\
\hline $\begin{array}{l}\text { Obstructive lesion } \geq 50 \% \\
\text { h/o MI without revascularization }\end{array}$ & $\begin{array}{c}11(24 \%) \\
3(7 \%)\end{array}$ \\
\hline
\end{tabular}

Continuous variables are expressed as mean \pm standard deviation; nominal variables are expressed as number (\%). See text for variable definitions.

and out of these 20 (61\%) had BB therapy withheld for $>48$ hours during their hospitalization. Twenty-seven (60\%) patients were discharged on a BB. Among the patients who were administered a BB postoperatively, the mean time between OLT and start of beta-blockade was $2.4 \pm 4.9$ days. Eight patients (18\%) were on statin therapy chronically and had the drug continued to the time of OLT. Following transplantation, 1 patient (2\%) was discharged on a statin. 
Tables 4 and 5 display the outcomes of myocardial infarction, death, and hospital length of stay following OLT. In our cohort, 5 patients (11\%) experienced an in-hospital MI. Of these, 4 occurred in patients that had BB therapy withdrawn (Figure $1)$, although this was not a statistically significant difference as compared to patients in whom BB therapy was uninterrupted (p $=0.118$ ). Of the 5 patients with in-hospital MI, one was on statin therapy. In total, there were 5 deaths $(11 \%)$ at 12 months posttransplant, 3 on $\mathrm{BB}$ at discharge and none on statin therapy at discharge. Composite 1-year mortality and MI was $22 \%$ and did not differ with regard to BB (provided 22\%; not provided 22\%; p $=0.637$ ) or statin prescription (provided $0 \%$; not provided $23 \%$; $\mathrm{p}=0.601$ ) at the time of discharge (Figure 2).

Lastly, univariate analysis revealed that mean LOS differed with respect to BB use and was longer in those that had interrupted (20.3 \pm 13.9 days) compared with uninterrupted BB therapy $(11.5 \pm 7.1 ; p=0.020)$ (Figure 3). LOS did not vary between those provided preoperative statins (13.6 days) compared to those that were not (17.0 days; $\mathrm{p}=0.422$ ).

\section{Discussion}

The significant prevalence of CAD in the ESLD population has recently been recognized, and the presence of CAD has been

Table 3: Peri-operative Beta-blocker and Statin use.

\begin{tabular}{|c|c|c|}
\hline & $\begin{array}{c}\text { Beta- } \\
\text { blocker }\end{array}$ & Statin \\
\hline 30 days prior to hospital admission for OLT \\
surgery & $33(73 \%)$ & $8(18 \%)$ \\
\hline Day of admission to hospital for OLT surgery & $28(62 \%)$ & $8(18 \%)$ \\
\hline Immediately pre-anesthesia for OLT surgery & $24(53 \%)$ & $8(18 \%)$ \\
\hline Discharge from hospital following OLT & $27(60 \%)$ & $1(2 \%)$ \\
\hline 30 days following OLT & $28(62 \%)$ & $2(4 \%)$ \\
\hline
\end{tabular}

All values are expressed as number (\%).

Table 4: 30 days Outcomes and Peri-operative BB and Statin Therapy.

\begin{tabular}{|c|c|c|c|c|c|c|c|}
\hline & \multirow{3}{*}{$\begin{array}{c}\text { All } \\
\mathrm{n}=45\end{array}$} & \multicolumn{2}{|c|}{ BB Withdrawn } & \multirow{3}{*}{$\begin{array}{c}p \\
\text { value }\end{array}$} & \multicolumn{2}{|c|}{$\begin{array}{c}\text { Perioperative } \\
\text { Statin }\end{array}$} & \multirow{3}{*}{$\begin{array}{c}p \\
\text { value }\end{array}$} \\
\hline & & \multirow{2}{*}{$\begin{array}{c}\text { Yes } \\
(n=20)\end{array}$} & \multirow{2}{*}{$\begin{array}{c}\text { No } \\
(n=13)\end{array}$} & & Yes & No & \\
\hline & & & & & $(n=8)$ & $(n=37)$ & \\
\hline Death & 0 & 0 & 0 & & 0 & 0 & \\
\hline MI & $5(11 \%)$ & $4(20 \%)$ & 0 & 0.12 & $1(13 \%)$ & $4(11 \%)$ & 0.64 \\
\hline LOS & $\begin{array}{c}16.4 \pm \\
11.6\end{array}$ & $\begin{array}{c}20.3 \pm \\
13.9\end{array}$ & $\begin{array}{c}11.5 \pm \\
7.1\end{array}$ & 0.02 & $\begin{array}{c}13.6 \pm \\
9.3\end{array}$ & $\begin{array}{c}17.0 \pm \\
12.1\end{array}$ & 0.42 \\
\hline
\end{tabular}

Continuous variables are expressed as mean \pm standard deviation nominal variables are expressed as number (\%). See text for variable definitions.

Table 5: 12 months Outcomes and Peri-operative BB and Statin Therapy.

\begin{tabular}{|c|c|c|c|c|}
\hline \multirow{2}{*}{} & Total & \multicolumn{2}{|c|}{ Discharge BB } & \multicolumn{1}{|c|}{} \\
\cline { 2 - 5 } & & Yes & No & \\
\cline { 2 - 5 } & $(\mathrm{n}=45)$ & $(\mathrm{n}=27)$ & $(\mathrm{n}=18)$ & p value \\
\hline Death & $5(11.1 \%)$ & $3(11.1 \%)$ & $2(11.1 \%)$ & 0.68 \\
\hline MI & $6(13.3 \%)$ & $4(14.8 \%)$ & $2(11.1 \%)$ & 0.54 \\
\hline Composite Death and MI & $10(22.2 \%)$ & $6(22.2 \%)$ & $4(22.2 \%)$ & 0.64 \\
\hline
\end{tabular}

All values are expressed as number (\%).

\section{Rate of 30-day MI vs. perioperativeBB therapy}

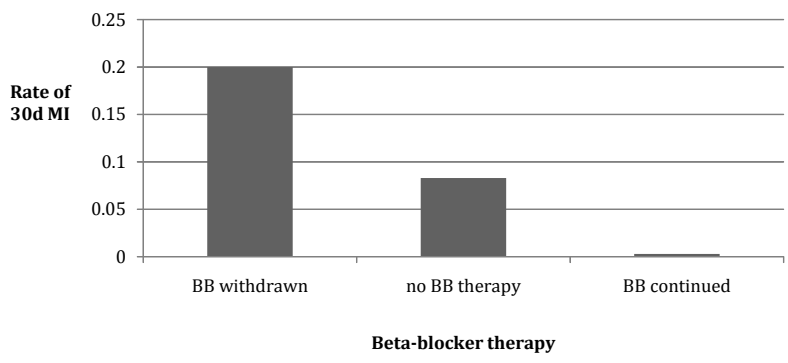

Rate of 30-day MI vs. perioperative BB therapy

Figure 1: Rate of 30-day MI vs. perioperative BB therapy.

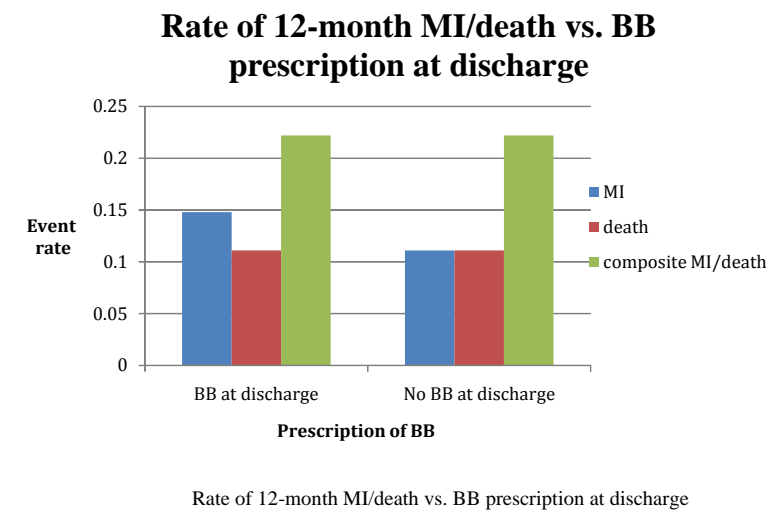

Figure 2: Rate of 12-month MI/death vs. BB prescription at discharge.

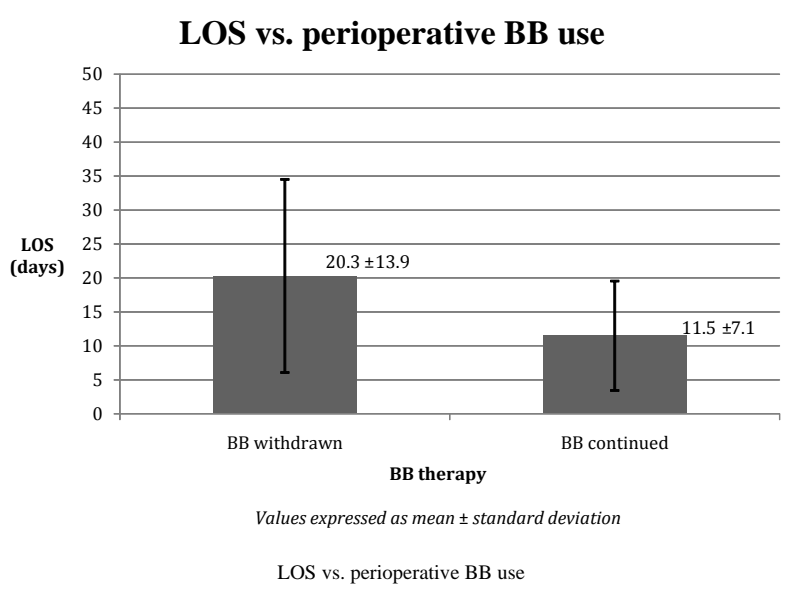

Figure 3: LOS vs. perioperative BB use.

demonstrated to predict poor outcomes in patients undergoing OLT. Three-year mortality rates in this population have been reported as high as $50 \%$, with half of the deaths occurring in the first 35 days after transplant [5]. In addition, cohort studies by Deidrich et al. [6] and Yong et al. [7] have established that this population fares reliably worse than those without known CAD. The present study identified high 1 year-mortality (11\%), MI 
(13\%), and composite mortality/MI (22\%) rates, similar to those identified in the aforementioned cohorts.

Management of perioperative cardiovascular risk in this population might include the provision of $\mathrm{BB}$ and statin drugs - the continuation of which is recommended in an effort to reduce cardiovascular events and mortality in those with CAD undergoing high risk surgeries [11-16]. We identified a high rate of perioperative BB withdraw - for which there are several potential explanations. At baseline, patients with cirrhosis are peripherally vasodilated and have low systemic vascular resistance, [17] and hypotension is often more pronounced around the time of transplant due to complicating occurrences (e.g. hemorrhage, sepsis), or the sudden hemodynamic changes that accompany liver transplantation [18]. An alternative explanation for frequent perioperative $\mathrm{BB}$ withdrawal is that many OLT candidates might have been initiated on chronic nonselective $\mathrm{BB}$ therapy for variceal bleeding prophylaxis, rather than for cardiac indications. Since acquisition of a healthy liver mitigates the risks of variceal bleeding, patients on nonselective beta-blockers prior to transplant may have these drugs discontinued perioperatively despite having CAD as an indication for continuation.

Importantly, we observed a trend toward increased 30-day MI and a statistically significant increase in hospital LOS among those with BB withdraw. In a retrospective study of 403 patients (with and without CAD) undergoing OLT, BB use was associated with reduced 30-day mortality and reduced 30-day death and myocardial infarction [8]. Whether or not the LOS or trend toward increased $\mathrm{MI}$ in the present investigation are related to $\mathrm{BB}$ withdraw, or representative of interceding co-morbidities is unclear but warrants further investigation in a prospective fashion.

Regarding statin therapy, few patients were on a statin at the time of OLT, most were not administered a statin postoperatively, and there was no relationship between statin therapy and outcomes. We speculate that common concerns regarding statin use in the OLT community may include 1) statin-associated transaminitis following OLT complicating the detection of acute rejection, and 2) fear of potential hepatotoxicity associated with statin use. Results from studies in patients with elevated liver enzyme levels, non alcoholic fatty liver disease, hepatitis $\mathrm{C}$, and cirrhosis have shown benefit of statin therapy without increased risk of adverse effects [19]. In addition, between $16 \%$ and $43 \%$ of liver transplant recipients have increased plasma cholesterol levels (in part due to their immunosuppressive regimens), $[20,21]$ and achievement of therapeutic goals among OLT patients is attainable with a low incidence of adverse events [22]. Thus, while the theoretical risk of confusing a statin-associated rise in liver enzymes with acute rejection remains a concern in patients with CAD undergoing OLT, prospective trials are needed to weigh the risk/benefit of statin administration in this setting.

To our knowledge, the present study represents the largest reported cohort of patients with CAD who underwent OLT, and the only one that describes patterns of $\mathrm{BB}$ and statin use in this population, along with associated outcomes. However, the present study has limitations: it is retrospective and single center. Moreover, although significant with respect to patterns of statin use, the number of patients on statin therapy in this population was low, precluding meaningful conclusions regarding outcomes.

Whether perioperative beta-blockers and statins improve outcomes in patients with CAD undergoing liver transplantation is unknown. Our study suggests a protective effect of continuing $\mathrm{BB}$ therapy perioperatively in those already taking a $\mathrm{BB}$, but our results may be confounded by the medical complications of transplant that might necessitate interruption of BB therapy. Nonetheless, our observations call for identifying reasons for BB withdrawal and provide support for increased vigilance with respect to $\mathrm{BB}$ provision in this population. Prospective trials are needed to elucidate the impact of both beta-blockers and statins on CAD patients undergoing OLT. If these therapies are shown to be advantageous, then patients who have historically been excluded from consideration may eventually benefit from this lifesaving surgery.

\section{Acknowledgement}

We thank Kim M Olthoff, MD, Abraham Shaked MD, PhD and the Penn Transplant Institute for their support.

\section{References}

1. Blei AT, Mazhar S, Davidson CJ, Flamm SL, Abecassis M, Gheorghiade M. Hemodynamic evaluation before liver transplantation: insights into the portal hypertensive syndrome. J Clin Gastroenterol. 2007; 41: S323-329.

2. Tiukinhoy-Laing SD, Rossi JS, Bayram M, De Luca L, Gafoor S, Blei A, et al. Cardiac hemodynamic and coronary angiographic characteristics of patients being evaluated for liver transplantation. Am J Cardiol. 2006; 98(2): 178-181.

3. Carey WD, Dumot JA, Pimentel RR, Barnes DS, Hobbs RE, Henderson JM, et al. The prevalence of coronary artery disease in liver transplant candidates over age 50. Transplantation. 1995; 59(6): 859-864.

4. Keeffe BG, Valantine H, Keeffe EB. Detection and treatment of coronary artery disease in liver transplant candidates. Liver Transpl. 2001; 7(9): 755-761.

5. Plotkin JS, Scott VL, Pinna A, Dobsch BP, De Wolf AM, Kang Y. Morbidity and mortality in patients with coronary artery disease undergoing orthotopic liver transplantation. Liver Transpl. 1996; 2(6): 426-430.

6. Diedrich DA, Findlay JY, Harrison BA, Rosen CB. Influence of coronary artery disease on outcomes after liver transplantation. Transplantation Proceedings. 2008; 40(10): 3554-3557. doi: 10.1016/j.transproceed.2008.08.129.

7. Yong CM, Sharma M, Mchoa V, Abnousi F, Roberts J, Bass NM, et al. Multivessel coronary artery disease predicts mortality, length of stay, and pressor requirements after liver transplantation. Liver Transpl. 2010; 16(11): 1242-1248. doi: 10.1002/lt.22152.

8. Safadi A, Homsi M, Maskoun W, Kathleen A Lane, Inder Singh, Sawada SG et al. Perioperative risk predictors of cardiac outcomes in patients undergoing liver transplantation surgery. Circulation. 2009; 120: 1189-1194. doi: 10.1161/CIRCULATIONAHA.108.847178.

9. Ehtisham J, Altieri M, Salamé E, Saloux E, Ollivier I, Hamon M. Coronary artery disease in orthotopic liver transplantation: pretransplant assessment and management. Liver Transpl. 2010; 16(5): 550-557. doi: $10.1002 /$ lt.22035.

10. Della Rocca G, Costa MG, Pompei L, Chiarandini P. The liver transplant 
recipient with cardiac disease. Transplant Proc. 2008; 40(4): 11721174. doi: 10.1016/j.transproceed.2008.03.070.

11. Fleisher LA, Beckman JA, Brown KA, Hugh Calkinset, Elliot L Chaikof, Kirsten E Fleischmann et al. 2009 ACCF/AHA focused update on perioperative beta blockade incorporated into the ACC/AHA 2007 guidelines on perioperative cardiovascular evaluation and care for noncardiac surgery. J Am Coll Cardiol. 2009; 54(22): e13-e118. doi:10.1016/j.jacc.2009.07.010.

12. Goldman L. Noncardiac surgery in patients receiving propranolol: Case reports and recommended approach. Arch Intern Med. 1981; 141(2): 193-196.

13. Shammash JB, Trost JC, Gold JM, Berlin JA, Golden MA, Kimmel SE Perioperative beta-blocker withdrawal and mortality in vascular surgical patients. Am Heart J. 2001; 141(1): 148-153.

14. Hoeks SE, Scholte Op Reimer WJ, van Urk H, Jörning PJ, Boersma E Simoons ML et al. Increase of 1-year mortality after perioperative beta-blocker withdrawal in endovascular and vascular surgery patients. Eur J Vasc Endovasc Surg. 2007; 33(1): 13-19.

15. Hindler K, Shaw AD, Samuels J, Fulton S, Collard CD, Riedel B. Improved postoperative outcomes associated with preoperative statin therapy. Anesthesiology. 2006; 105(6): 1260-1272.

16. Le Manach MY, Godet G, Coriat P, Martinon C, Bertrand M, Fléron MH et al. The impact of postoperative discontinuation or continuation of chronic statin therapy on cardiac outcome after major vascular surgery. Anesth Analg. 2007; 104(6): 1326-1333.
17.Cichoz-Lach H, Celinski K, Slomka M, Kasztelan-Szczerbinska B. Pathophysiology of portal hypertension. J Physiol Pharmacol. 2008; 59: 231-238.

18. Tandon P, Ma M, Lee SS, Waleed K Al-Hamoudi, Saleh Alqahtan. Hemodynamics in the immediate post-transplantation period in alcoholic and viral cirrhosis. World J Gastroenterol. 2010; 16(5): 608612. doi: 10.3748/wjg.v16.i5.608.

19. Onofrei MD, Butler KL, Fuke DC, Miller HB. Safety of statin therapy in patients with preexisting liver disease. Pharmacotherapy. 2008; 28(4): 522-529. doi: 10.1592/phco.28.4.522.

20. Russo MW, Jacobson IM. How to use statins in patients with chronic liver disease. Cleve Clin J Med. 2004; 71(1): 58-62.

21. Reuben A. Long-term management of the liver transplant patient: diabetes, hyperlipidemia, and obesity. Liver Transpl. 2001; 7(11): S13-21.

22. Martin JE, Cavanaugh TM, Trumbull L, Bass M, Weber F Jr, Aranda-Michel $J$ et al. Incidence of adverse events with HMG-CoA reductase inhibitors in liver transplant patients. Clin Transplant. 2008; 22(1): 113-119. doi: 10.1111/j.1399-0012.2007.00780.x.

23. Thygesen K, Alpert JS, Allan S Jaffe, Maarten L Simoons, Bernard R Chaitman, White HD. Universal definition of myocardial infarction. Eur Heart J. 2007; 28: 2525-2538. 